\title{
PIXELAR A PLATÓN
}

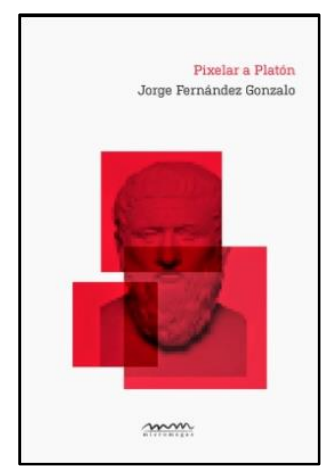

JORGE FERNÁNDEZ GONZALO,

MURCIA, EDITORIAL MICROMEGAS, 2015

264 PÁGS. ISBN. 9788494054570

Pablo Porto López

$(U B A)$

El incremento exponencial en el volumen de producción académica sobre entornos digitales, producto de la fulgurante aparición de los nuevos medios -medios digitales, meta o hipermedia según la denominación que se prefiera-, no ha tenido un correlato semejante en los estudios sobre videojuegos. Tal vez esto se deba a que lo lúdico no haya sido siempre considerado un objeto de pleno derecho en filosofía o ciencias sociales; o tal vez aquella carencia pueda explicarse, en cambio, porque el funcionamiento interactivo de los videojuegos habría quedado ya de manifiesto mucho antes de la popularización de Internet y del hipertexto, de modo que lo que en un caso fue revolución, en el otro significó únicamente la profundización de una tendencia preexistente.

Sea cual fuere la causa de estos desequilibrios en el output productivo de la academia, Pixelar a Platón tiene el indiscutible mérito de no solamente presentar una reflexión profunda sobre los videojuegos, sino de colocarlos en el lugar de interpretante de la sociedad y del sujeto contemporáneos. Es un movimiento que ha sido ensayado con lo literario, lo cinematográfico o lo televisivo; la particularidad de este libro reside en que Jorge Fernández Gonzalo nos propone pensar las condiciones de la vida económica, artística y política, así como los mecanismos sociales de constitución de la subjetividad, desde lo videolúdico. La máquina de videojuegos, entendida como un dispositivo de producción de sentido, o mejor, de producción conceptual, se inserta en la línea de filiación de otras máquinas productoras de ideas, como la que da lugar a lo cinematográfico. Pero los videojuegos encuentran en esta obra su lugar, su especificidad: si la máquina fílmica, como señaló Deleuze, produce ideas a partir de imágenes-movimiento e imágenes-tiempo, ¿qué sucede con los videojuegos? ¿Cuál sería su gramática epistemológica particular?

Resulta evidente, desde el comienzo del libro, que no hay una pretensión de "capturar" el objeto videojuego desde el campo del pensamiento filosófico sino, antes bien, de crear un espacio para que emerja el modo de expresión o producción conceptual propio de lo videolúdico: "Las ficciones interactivas piensan no con conceptos o a través de coordenadas metafísicas, sino con gráficos y reglas, entornos y mecánicas de juego". Se nos propone ejercitar un pensamiento filosófico, pero regido por otros parámetros de producción conceptual. "Pixelar a Platón" implica, en este sentido, poner en fase filosofía y videojuegos, hallar ese nivel específico de resonancia recíproca en que el efecto a la vez constructivo y disruptivo de estos últimos abre las posibilidades a un pensamiento "ludosófico", según la nomenclatura del autor.

¿En qué términos habrá de plantearse entonces la alegoría germinal de la filosofía en una era de videojuegos? La propuesta del libro consiste en invertir el modelo platónico de la caverna: las sombras, las apariencias, nos dirá el filósofo español, son capaces de generar su "Cosa real" que nos interpela y nos permite, a través suyo, comprender nuestras condiciones de existencia. El camino que se abre a partir de esta constatación no puede ser otro que el de descubrir la verdad que se aloja en las apariencias. Si las sombras no pueden ser vistas ya como un velo que es necesario trascender, plano ilusorio de ocultamiento de la verdad o simulacro de un real exterior que es representado allí de modo más o menos deformante, es porque son justamente esas sombras las que estructuran el campo social y el sujeto. A partir de esa premisa, el libro describe un recorrido que transpone la ficción platónica en 
tanto que sombra de una sombra -fantasma de un real que no existe o máscara de un rostro que no está allí-, desde los muros de la caverna hasta la pantalla del videojuego.

La alegoría del filósofo ateniense es el disparador sobre el que convergerán conceptos del psicoanálisis lacaniano que, con una fuerte impronta de los desarrollos posteriores de Deleuze y Guattari, será puesto en permanente diálogo con ideas de otros pensadores como Baudrillard, Virilio o Žižek, las cuales servirán de balizas para un camino que se antoja no exento de dificultades. No ya la realidad, sino lo Real en sentido lacaniano, se mostraría a través de las pantallas en general, y de la pantalla videolúdica en particular, como resto inasible o no simbolizable, como mancha, grieta o fisura. La palabra que escoge el autor, y sobre la que vuelve en reiteradas ocasiones, para dar cuenta de este fenómeno es "escotoma".

Paralelamente, el libro recupera trabajos específicos del campo de los estudios sobre los videojuegos y la cibercultura, convocando a algunos de sus grandes exponentes, como Espen Aarseth o Sherry Turkle, y a un conjunto de autores españoles que han asimismo trabajado de manera profunda sobre estas temáticas. Fernández Gonzalo se mueve con soltura y naturalidad entre diferentes campos de saber: el cine, la literatura, el arte moderno e incluso la historia de los medios. No es un gesto de erudición vacío, pues estos saberes son convocados en pos de la dilucidación del objeto de análisis o, mejor, confluyen para una cuidadosa "puesta a punto" de la máquina conceptual que el autor se propone emplear.

En este sentido, es un acierto del libro, que gana en profundidad analítica, el complementar su enfoque "ludosófico" con una genealogía de la máquina videolúdica. Se propone un recorrido por una serie de dispositivos que han contribuido a conformar la cultura visual moderna, y que encontraremos posteriormente desplegados y plenamente operativos en los videojuegos: desde aquellos que procuraban engañar al ojo -la linterna mágica o el fenaquistiscopio, entre otros-, hasta los que pretendían reproducir la realidad -como la fotografía-, gesto tan propio del naturalismo decimonónico y del sistema técnico indicial de medios al que diera lugar. Pero ésta no es la única genealogía que el autor reconstruye, pues el videojuego se inscribe en la serie de lo (audio)visual tanto como en la del juego, cuya historia abarca manifestaciones tan variadas como el "tres en línea", los dados, los juegos de rol o las carreras. Esto es lo que, para Fernández Gonzalo, convierte al videojuego en una máquina total que une la "sociedad del ocio con el status posmediático de la imagen contemporánea".

El recorrido histórico se complementa con una visión sistémica de los medios según la cual no se puede comprender a los videojuegos si se los analiza de forma aislada; por el contrario, será necesario pensarlos de manera ecológica en relación con todos los otros medios con que conviven. De hecho, no faltan referencias a McLuhan, Manovich, Jenkins, o incluso a David Cronenberg, cuyos films Existenz y Videodrome, ambos examinados en este libro, evidencian la influencia mcluhaniana hasta el punto de materializar de manera literal la tesis según la cual los medios son especies biológicas.

Más allá del necesario y extenso recorrido tanto histórico como bibliográfico que no s propone el autor, podemos estar de acuerdo con que quizá "el primer gesto que deba llevarse a cabo en una aproximación ludosófica al campo de los videojuegos sea el de enganchar una Playstation a la pantalla de sombras que surge en la caverna de Platón”. Y no caben dudas de que Fernández Gonzalo lo ha hecho de sobra. El libro abarca a un enorme número de títulos que van desde juegos mainstream de acción, aventura o terror como Grand Theft Auto, Uncharted, Assasins Creed, Tomb Raider, Silent Hill, Portal o Max Payne, a juegos de estrategia como Civilization o Age of Empires, y que incluye hasta clásicos del arcade como el Tetris, el Pac-man, el Space Invaders o el Pong, pasando por juegos de rol online -podemos mencionar a Second Life y World of Warcraft entre los ejemplos más notables-, o por títulos poco conocidos producto de movimientos de "ludorresistencia", caracterizados por vehiculizar críticas a la economía capitalista, la intolerancia étnica o el fundamentalismo religioso, como puede apreciarse en McDonald's Videogame o en Faith Fighter. Y esto representa sólo una fracción de las paradas viodeolúdicas que el trayecto del libro nos propone. 
Pese a la cantidad apabullante de títulos abordados, lejos están de ser tratados de manera superficial, puesto que el autor se detiene lo suficiente como para introducir al lector en cada uno, presentando con claridad y detalle los principios narrativos y funcionales que estructuran cada uno de estos mundos. Fernández Gonzalo realiza una lectura que podemos calificar de barthesiana -del Barthes de S/Z-, según la cual interpretar un texto no es conferirte un solo sentido más o menos fundado, sino explorar, recorrer, apreciar el plural del que está hecho, liberar el juego múltiple de sus redes de significantes sin que ninguna determine a las otras, aunque esto arroje como resultado que de un mismo título de videojuego puedan construirse interpretaciones alternativas o incluso en conflicto.

Pese a la clasificación necesariamente sesgada por una mirada fundada en lo genérico (acción, terror, estrategia, rol, etc.) que acabamos de ensayar más arriba, cada juego es abordado por el libro desde niveles múltiples: se despliega un verdadero hojaldre de capas analíticas entre las que encontramos las técnicas de planos y puntos de vista, la simbología o la interpretación psicoanalítica, la representación del espacio y del tiempo, la estructuración hipertextual e interactiva -como algo diferente de lo iterativo o lo meramente espectatorial, presentes también en lo videolúdico-, el nivel de libertad del que disfruta el jugador o el tipo accesorio protésico que le es propuesto por el juego. Los diferentes estratos de análisis hacen su aparición en función del tema a ser tratado, temas que van desde la relación fundante, originaria, de videojuego y guerra, esto es, el videojuego como resultado histórico de desarrollos tecnológicos ligados a finalidades bélicas, hasta sus relaciones con la política y el arte, con el capitalismo y el multiculturalismo, con la violencia y la libertad, con la construcción del cuerpo y la estructuración del inconsciente, con la creación de emociones y el empleo de interfaces para la comunicación hombre/máquina. El libro destina capítulos completos al tratamiento de cada uno de estos temas.

Pero sin dudas el eje que estructura y recorre toda la obra es aquel que pretende cartografiar la conflictiva relación entre videojuego y realidad: la experiencia videolúdica es conceptualizada por Fernández Gonzalo como traspaso de esas fronteras, como profanación del límite entre ambos planos, que por su propio accionar se vuelve poroso, agrietado. La contaminación entre lo digital y lo analógico va en ambos sentidos: por un lado, el sujeto se puede incorporar al juego, operar esta solución del quiebre ontológico entre destinatario y obra por medio del escaneo del rostro o de la captura de sus movimientos a través de cámaras y sensores; pero al mismo tiempo, el videojuego puede trasponer el umbral de la pantalla para ingresar al mundo analógico. Estas reflexiones se tocan con la cuestión de la hiperrealidad, que aparece abordada de manera magistral por el libro, y que enfoca el modo en que el mundo real ha adoptado muchas de las características de un juego de simulación. Esta irrupción de los juegos en la realidad, ese "desbordamiento de lo virtual" en el plano de nuestras experiencias analógicas y la consiguiente "colonización de los códigos simbólicos" de nuestro mundo como parte de una "estrategia lúdico-performativa", se manifiesta de manera rotunda con la llamada realidad aumentada. En este punto, Fernández Gonzalo habla de Ingress como el primer juego de una clase que alcanzaría el éxito y la masividad mundiales con Pokémon GO, de aparición algo posterior al libro, pero cuya relevancia había sido ya prevista por éste.

Para finalizar, diremos que ya desde el índice, así como en muchos otros paratextos y secciones del libro, encontramos remisiones constantes a la jerga de los videojuegos: nos topamos con mundos, niveles de dificultad, y somos designados, en tanto que lectores, con apelativo de "jugador 1". Estos indicios no son un mero detalle de color. El "programa" de pensar al videojuego desde sí mismo, se materializa en la propia estructura de la obra, la cual pretende emular, como el autor mismo lo señala, una partida de Súper Mario Bros. Así, se ofrecen atajos al lector, "tuberías secretas" que permiten saltear definiciones o profundizar en determinado tema, y pasar directamente a otro capítulo. Por otro lado, luego de haber recorrido una parte significativa de la obra, accedemos a "desbloqueos de logros", recompensas características de muchos videojuegos, que aquí aumentan los "puntos de experiencia" del lector mediante una invitación, vía hipertexto, a contenidos vinculados pero alojados en la web. Asimismo, hacia el final de algún capítulo, no dejaremos de tener que enfrentarnos ante "enemigos de fase" o nivel, marca de fábrica de los arcade de la década del 80, que aquí se manifiestan bajo la forma de conceptos fundamentales a los que debemos necesariamente hacer frente para continuar con el recorrido propuesto por el libro. 
Pese a la confesión voluntaria del autor de que ésta no es más que una "falsa interactividad", resultado del esfuerzo jamás plenamente logrado del formato libro por recrear la hipertextualidad que sí posee su objeto de estudio, el gesto ilustra, por medio de una analogía estructural, uno de los puntos clave de Pixelar a Platón: la resistencia que ofrece lo videolúdico como objeto de conocimiento a cualquier pensamiento (o discurso) otro. Es que, como señala Fernández Gonzalo, no se trata de pensar a los videojuegos desde la filosofía, sino de servirse de lo videolúdico para pensar al sujeto y a la sociedad que los produce. 